\title{
Demographics and functional outcome of toe fractures
}

S.T. Van Vliet - Koppert ${ }^{1}$, H. Cakir ${ }^{1}$, E.M.M. Van Lieshout ${ }^{2}$, M.R. De Vries ${ }^{1}$, M. Van Der Elst ${ }^{1}$, T. Schepers ${ }^{1}$

${ }^{1}$ Department of General Surgery and Traumatology, Reinier de Graaf Groep, Delft, the Netherlands

${ }^{2}$ Department of Surgery-Traumatology, Erasmus MC, University Medical Center Rotterdam, Rotterdam, the Netherlands

Corresponding author

T. Schepers, MD, PhD

Department of General Surgery and

Traumatology

Reinier de Graaf Groep Delft

PO Box 5011

2600 GA Delft

The Netherlands

Tel: $+31-15-2603060$

Fax: $+31-15-2603599$

This study was financially supported by the WAC (Wetenschappelijke Activiteiten Commissie) of the Reinier de Graaf Groep Delft 


\section{Abstract}

Introduction: Toe fractures are among the most common fractures of the foot. There is however little data on demographics and functional outcome.

Method: All consecutive patients with toe fractures treated between January 2006 and September 2008 were re-evaluated. Patients aged 16 to 75 (264 patients) were sent an outcome questionnaire based on the American Orthopaedic Foot Ankle Society Midfoot Scale. Overall satisfaction with treatment outcome was measured using a Visual Analogue Scale.

Results: A total of 339 patients with 368 digital and 370 phalangeal fractures of the foot were identified. Most frequently affected were the first (38\%) and fifth (30\%) toe. Most fractures were caused by stubbing or crush injury (75.6\%). More than $95 \%$ of the fractures were less than $2 \mathrm{~mm}$ displaced. All fractures were treated conservatively. The questionnaire was returned by 141 patients $(53 \%)$ with a median follow-up of 27 months. Respondents were female in $57.4 \%$ and had a median age of 45 years. In $46.8 \%$ of cases the left side was affected. The median AOFAS-score was 100 points, the median VAS was 10 points. In the univariate analysis no correlations were identified with outcome and which toe or phalangeal bone was affected, number of fractured toes, fracture type and location, articular involvement, gender, age, body mass index, smoking habits, and diabetes. The VAS was dependent of age $(p=0.047)$ and gender $(p=0.049)$ in the multivariate analysis. The AOFAS Midfoot Score was not influenced by any of the parameters.

Conclusion: This is the first investigation using two validated outcome scoring systems to determine functional outcome in toe fractures. Almost all toe fractures were healed without complaints at 27 months.

Keywords: toe, phalangeal, foot, injury, fracture, epidemiology, outcome 


\section{Introduction}

Toe fractures or digital fractures of the foot are among the most common fractures of the foot with an incidence ranging from 14.0 to 39.6 patients per 10,000 persons per year (1-4). Their prevalence varies from 3.0 percent of fractures in children to 3.6 percent of all fractures in adults $(1,4)$. However, previous studies lack data on demographics and fracture-patterns of toe fractures.

Almost all toe fractures can be treated well conservatively with an expected overall good outcome, especially considering the lesser toes $(3,5-7)$. To date, the functional outcome and patient satisfaction after a toe fracture have not been investigated.

The aim of the current study was twofold: The first aim was to evaluate the demographics of toe fractures in a Level-2 trauma centre, providing care for an area of over 300,000 patients. In addition, the functional outcome and patient satisfaction after a digital fracture of the foot was determined using validated outcome scoring systems. 


\section{Patients and methods}

\section{Demographics}

All consecutive patients with a toe fracture caused by an isolated trauma to the foot, between January 1, 2006 and June 31, 2008, were extracted from the Emergency Department registries, following approval of the local medical ethics board. The initial radiographs performed at the Emergency Department were re-evaluated by two observers (TS, SV). Patient characteristics (e.g., age, body mass index (BMI), gender, diabetes, smoking habits, and side of injury) were collected. Moreover, data on the fracture characteristics (i.e., which toe and phalanx was involved, the number of involved toes, joint involvement, type of fracture (transverse, oblique/spiral, comminution, and avulsion), the fracture level (distal, shaft, proximal), the amount of displacement (zero, less than $2 \mathrm{~mm}, 2$ to $5 \mathrm{~mm}$, and more than $5 \mathrm{~mm}$ ), and the trauma mechanism (suppination, fall from height, crush, stub, and stress fracture) were collected from the medical charts.

Treatment in all patients was according to hospital protocol. Patients with a fracture of the great toe were treated with a cast for three weeks on average. Fractures of one or more of the lesser toes were treated with splinting to the adjacent toe. These patients were advised to wear a rigid-sole shoe.

\section{Functional outcome questionnaire}

A postal survey was developed according to existing guidelines to optimise response rates.(8) The recommendations of the American Association for Public Opinion Research (AAPOR) were carefully followed (9). All patients between the ages of 16 and 75 were sent a questionnaire containing the AOFAS Midfoot score and a single question Visual Analogue Scale. As physical exam of the patients (range of motion of the toe joints) was not possible the Hallux and Lesser metatarsophalangeal- 
interphalangeal AOFAS scores could not be applied as they rely heavily on the range of motion of the toes. The AOFAS Midfoot score was introduced by Kitaoka et al. in 1994. It includes questions on pain, activity and functional limitations, footwear, walking distance, difficulties with different terrains, gait, and alignment (whether or not plantigrade) (10). The seven questions relate to three components: Pain (1 question; maximum 40 points), Function (5 questions; maximum 45 points), and Alignment (1 question; maximum 15 points) leading to a total possible score of 100 points. The question related to alignment was completed by a physician based on patient-files and radiographs, the other questions were completed by the patient. The Visual Analogue Scale was used to measure overall satisfaction of patients with outcome (range zero to ten) (11). In addition, patients were asked about the ability to run, walk on their toes, and walk bare feet. After three weeks the non-respondents were sent a reminder, including the questionnaire and a return-envelope.

\section{Statistical analysis}

The statistical analysis was performed using the Statistical Package for the Social Sciences (SPSS) version 16.0 (SPSS, Chicago, IL). The Kolmogorov-Smirnov test was used to test for normality of the numeric data. The Levene's test was applied to assess homogeneity of variance between data. Since most numeric variables did not show normal distribution or equal variance, all items were regarded as nonparametric for the statistical analysis. Mann-Whitney U-tests were performed to assess statistical differences in AOFAS and VAS scores between subgroups (e.g., males versus females, smoking versus non-smoking, absence versus presence of diabetes, first digit fractures, and multiple fractures). Numeric data are expressed as medians with $\mathrm{P}_{25^{-}}$ $\mathrm{P}_{75}$; categoric data are shown as numbers with percentages. 
Logistic regression models were subsequently developed in order to correct for gender, age, diabetes, smoking habits, BMI, fracture-type, and fracturedislocation. A p-value $<0.05$ was taken as level of statistical significance. 


\section{Results}

\section{Demographics}

In the thirty-month study-period a total of 339 patients with 368 digital and 370 phalangeal fractures of the foot were identified. Two patients had two concurrent phalangeal fractures in the same digit. There were $172(50.7 \%)$ male patients and 167 (49.3) female. The median age of the group was 35.2 years $\left(P_{25}-P_{75}\right.$ 19.3-53.5). Male patients had a median age of 26.0 years $\left(P_{25}-P_{75}\right.$ 15.0-44.7), and female patients 43.3 years of age $\left(P_{25}-P_{75} 26.1-58.6\right)$. Patients aged five or less accounted for $2.7 \%$ of all patients. Patients aged twelve or less represented $15 \%$ of the study population. The right side was involved in 177 (51.9\%) patients and the left side in $164(48.1 \%)$. In two cases a bilateral digital injury was encountered, but with an interval of several weeks to the second injury.

The distribution of fractured toes was first metatarsal $38 \%$, second $11 \%$, third $7 \%$, fourth $14 \%$, and fifth $30 \%$ (Figure 1). Multiple metatarsal fractures were seen in 5.9 percent (two toes $4.4 \%$, three toes $0.9 \%$ and four toes 0.6 percent). The most frequently occurring trauma mechanisms were stubbing the toe $(51.6 \%)$, crush injuries $(24.0 \%)$, and supination injuries (11.2\%). Ninety-seven percent of fractures was not or minimally (less than $2 \mathrm{~mm}$ ) displaced. Transverse fractures occurred in $33 \%$, oblique or spiral in $41 \%$, comminute fractures in $13 \%$ and avulsion fractures in another $13 \%$. Involvement of phalangeal joint surface was seen in 122 cases (33\%), which was predominately at the base of the phalanx. All fractures were treated conservatively.

\section{Functional outcome questionnaire}

A total of 141 out of 264 patients (53\%) between 16 and 75 years of age returned the questionnaire with a median follow-up of 27.3 months $\left(P_{25}-P_{75}\right.$ 21.2-39.0). 
Respondents were female in $57.4 \%$ and the median age for the respondents was 44.7 years $\left(\mathrm{P}_{25}-\mathrm{P}_{75}\right.$ 30.8-58.3). The median $\mathrm{BMI}$ for the respondents was $23.9\left(\mathrm{P}_{25^{-}}\right.$ $\mathrm{P}_{75}$ 21.6-26.0). In $46.8 \%$ of cases the left side was affected. $A$ total of $7.4 \%$ of patients had diabetes and $25.7 \%$ were smokers.

In the respondent group 66 patients $(47 \%)$ were treated by splinting the fractured toe to an adjacent toe, and 44 cases (31\%) were treated with a cast. Three patients $(2 \%)$ received no splint or cast.

Most responders reported to be able to run $(84.4 \%)$, walk on the toes $(75.2 \%)$, and walk bare feet (82.3\%). Twenty-five patients (18\%) failed to answer these questions.

The median AOFAS Midfoot score was 100 points $\left(P_{25}-P_{75} 93-100\right)$ with an AOFAS Functional subscore of $45\left(\mathrm{P}_{25}-\mathrm{P}_{75} 45-45\right)$. The median VAS was 10 points $\left(\mathrm{P}_{25}-\mathrm{P}_{75} 8-10\right)$.

Respondents were comparable to non-respondents, except for age (36.9 versus 44.7 years).

\section{Statistical analysis}

No differences in outcome were identified for which toe or phalangeal bone was affected, number of fractured toes, fracture type and location, joint involvement, gender, age, body mass index, smoking habits, and diabetes (Table 1).

A statistically significant correlation was found between the AOFAS overall score, AOFAS Functional subscore and VAS (Table 2). These outcome scores showed no significant correlation with age or BMI $(p>0.05)$.

In the univariate analysis a trend was found for increased dislocation and lower AOFAS scores $(p=0.058)$. In the multivariable analysis the VAS was dependent on age $(p=0.047)$ and gender $(p=0.049)$. The AOFAS Midfoot score was not influenced by any of the parameters in the multivariable analysis. 


\section{Discussion}

The current study of 339 patients with 368 digital and 370 phalangeal fractures provides an improved insight in one of the most common fractures of the foot. However, this number of patients might be an underestimation, as an unknown number of patients may be treated by the General Practitioner or did not seek any medical attention at all. Previous studies reported an incidence of 14 to 40 per 10,000 patients (1-2).

Males and females were equally represented in the current study, as opposed to previous studies in which a male predominance of 62 to 66 percent was reported (13). The study by Rennie et al, on paediatric fracture epidemiology, showed a similar age-distribution as the current investigation (4). No comparison could be made with distribution data in the literature for adults (1-3).

The number of great toe fractures in this study (38\%) is higher than previously reported (17-24\%) (2).This difference might be due to the inclusion of paediatric patients, in whom a higher incidence of first digital fractures was seen $(41.9 \%$ below the age of 16$)$.

The median age of 35.2 years was almost similar to the age reported by Court-Brown et al, who reported an average age of 35.3 years with exclusion of patients aged below twelve (1). Rennie et al, looking at patients below sixteen, showed an average age of 10.9 years for toe fractures (4).

The secondary aim of this study was to evaluate functional outcome scores after the conservative treatment of toe fractures. Patients were sent a postal questionnaire in order to obtain the highest possible response rate. Hence, physical exam of the patients (range of motion of the toe joints) was not possible. Therefore we applied the American Orthopaedic Foot Ankle Society Midfoot Scale in the current study. The 
outcome scores in this population were excellent with a median of 100 points (AOFAS) and 10 points (VAS). Despite the response rate of $53 \%$, we can conclude that patient satisfaction after conservative treatment of toe fractures is high. We were not able to find any studies in the literature using outcome scores in toe fractures, comparisons were therefore not possible.

Because of the overall excellent scores both at the AOFAS Midfoot Score and on the VAS few predictors of outcome could be identified by the statistical analysis. Statistical analysis revealed a trend towards lower AOFAS scores in more displaced fractures in the univariate analysis There were no significant difference in outcome regarding type and location of the fracture. In their review on the management of toe fractures, Hatch et al. confirmed that most toe fractures treated conservatively lead to an excellent functional outcome, however they did not include any outcome score. ${ }^{6}$

A lower satisfaction with overall result (VAS) was found in younger female patients in the multivariate analysis. Female gender has been pointed out as predictor of less favourable outcome in ankle fractures earlier (12). This might be a more critical patient population with high demands on fashionable shoe-wear.

This study is the first on the epidemiology and functional outcome of toe fractures, showing that more than ninety-five percent of fractures was not or minimally displaced. Three-quarters of all fractures were transverse, oblique or spiral, and in more than seventy-five percent of cases the trauma mechanism was stubbing the toe or a crush injury. Excellent outcome was obtained with conservative treatment as measured by the AOFAS Midfoot Score and VAS after a median of 27 months.

In conclusion, toe fractures are common fractures of the foot. Conservative treatment of these injuries shows excellent outcome scores and a high patient satisfaction. Younger, female patients showed slightly less favourable outcome, and a trend was 
identified for less favourable outcome with increased displacement at the fracture side. Their distribution, patient, and fracture characteristics provided by this study may aid in the planning of future clinical trials concerning different treatment modalities. 


\section{References}

1. Court-Brown CM, Caesar B. Epidemiology of adult fractures: A review. Injury 37:691-697, 2006.

2. Schnaue-Constantouris EM, Birrer RB, Grisafi PJ, Dellacorte MP. Digital foot trauma: emergency diagnosis and treatment. J Emerg Med 22:163-170, 2002.

3. Mittlmeier T, Haar P. Sesamoid and toe fractures. Injury 35 Suppl 2:SB87-97, 2004.

4. Rennie L, Court-Brown CM, Mok JY, Beattie TF. The epidemiology of fractures in children. Injury 38:913-922, 2007.

5. Cobey JC. Treatment of undisplaced toe fractures with metatarsal bar made from tongue blades. Clin Orthop Relat Res:56, 1974.

6. Hatch RL, Hacking S. Evaluation and management of toe fractures. Am Fam Physician 68:2413-2418, 2003.

7. MacManus JE. The use of a plaster slipper in the management of simple fractures of the toes. Am J Surg:721-722, 1941.

8. Edwards P, Roberts I, Clarke M, DiGuiseppi C, Pratap S, Wentz R, Kwan I. Increasing response rates to postal questionnaires: systematic review. Bmj 324:1183, 2002.

9. Johnson T, Owens L. Survey response rate reporting in the professional literature. Presented at the 58th Annual Meeting of the American Association for Public Opinion Research, Nashville, May 2003. , 2003.

10. Kitaoka HB, Alexander IJ, Adelaar RS, Nunley JA, Myerson MS, Sanders M. Clinical rating systems for the ankle-hindfoot, midfoot, hallux, and lesser toes. Foot Ankle Int 15:349-353, 1994.

11. Schepers T, Schipper IB, Vogels LM, Ginai AZ, Mulder PG, Heetveld MJ, Patka P. Percutaneous treatment of displaced intra-articular calcaneal fractures. $\mathrm{J}$ Orthop Sci 12:22-27, 2007. 
12. Egol KA, Tejwani NC, Walsh MG, Capla EL, Koval KJ. Predictors of short-term functional outcome following ankle fracture surgery. J Bone Joint Surg Am 88:974-979, 2006. 
Figures and tables

Figure 1: Distribution of toe $(n=368)$ and phalangeal $(n=370)$ fractures according to their location

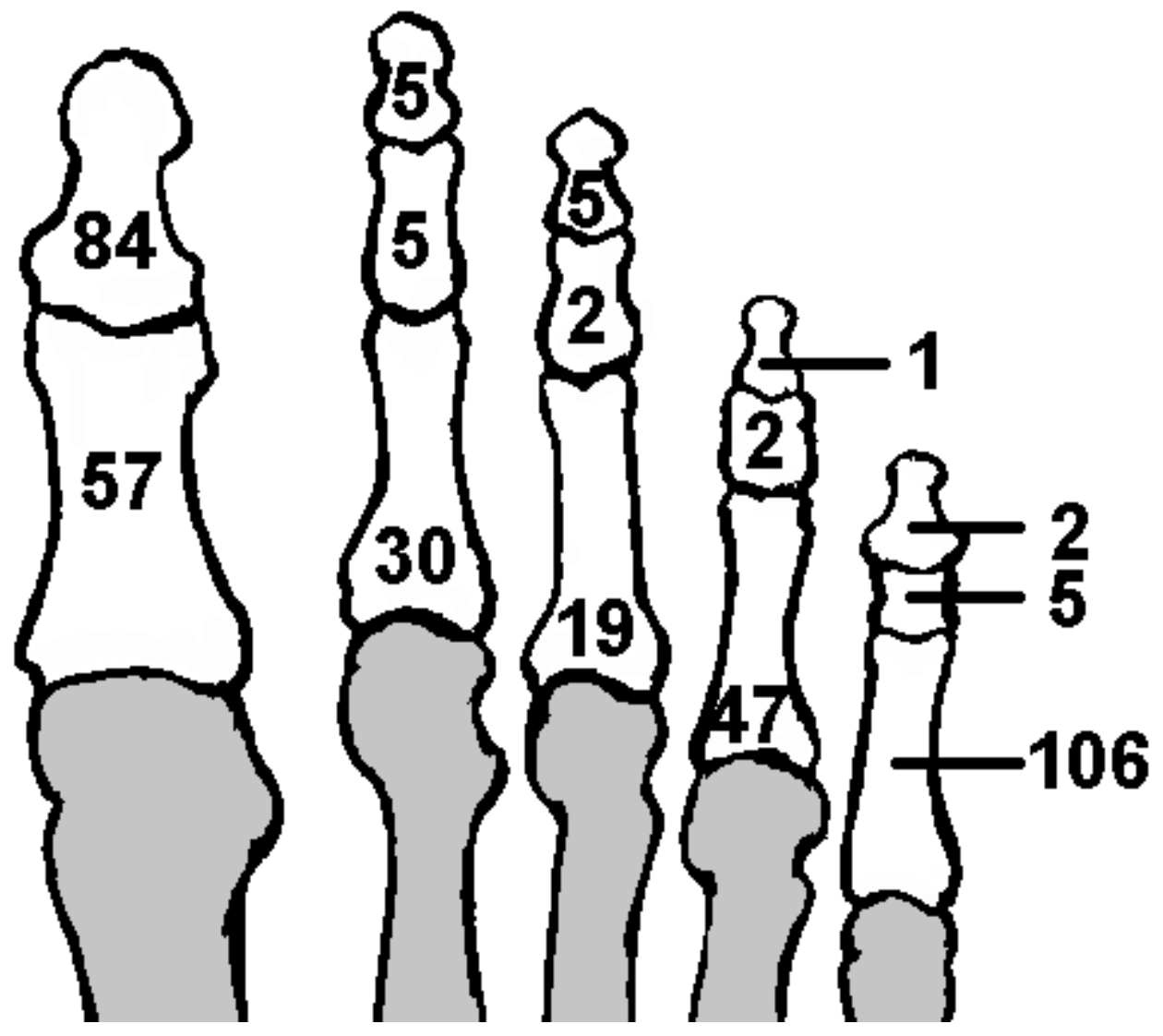


Table 1. Functional outcome scores per subgroup

\begin{tabular}{|c|c|c|c|c|}
\hline \multicolumn{2}{|c|}{ Patient or fracture characteristic } & \multirow[t]{2}{*}{ VAS } & \multirow{2}{*}{$\begin{array}{l}\text { AOFAS } \\
\text { functional } \\
\text { score }\end{array}$} & \multirow{3}{*}{$\begin{array}{l}\text { AOFAS total } \\
\text { score } \\
100(00-100)\end{array}$} \\
\hline & & & & \\
\hline \multirow[t]{2}{*}{ Smoking } & Yes & $9(8-10)$ & $45(45-45)$ & \\
\hline & No & $10(8-10)$ & $45(45-45)$ & $100(93-100)$ \\
\hline \multirow[t]{2}{*}{ Diabetes } & Yes & $9(8-10)$ & $45(43-45)$ & $93(89-100)$ \\
\hline & No & $10(8-10)$ & $45(45-45)$ & $100(93-100)$ \\
\hline \multirow[t]{2}{*}{ Gender } & Male & $10(8-10)$ & $45(45-45)$ & $100(93-100)$ \\
\hline & Female & $10(8-10)$ & $45(45-45)$ & $100(93-100)$ \\
\hline \multirow[t]{2}{*}{ Hallux fracture } & Yes & $10(8-10)$ & $45(44-45)$ & $100(93-100)$ \\
\hline & No & $10(8-10)$ & $45(45-45)$ & $100(93-100)$ \\
\hline Number of & Single fracture & $10(8-10)$ & $45(45-45)$ & $100(93-100)$ \\
\hline fractures & Multiple fractures & $9(8-10)$ & $45(45-45)$ & $100(80-100)$ \\
\hline \multirow[t]{2}{*}{ Fracture location } & Extra-articular & $10(8-10)$ & $45(45-45)$ & $100(93-100)$ \\
\hline & Intra-articular & $9(8-10)$ & $45(45-45)$ & $100(93-100)$ \\
\hline \multirow[t]{2}{*}{ Dislocation } & $<=2 \mathrm{~mm}$ & $10(8-10)$ & $45(45-45)$ & $100(93-100)$ \\
\hline & $>2 \mathrm{~mm}$ & $10(7-10)$ & $44(39-45)$ & $93(78-96)$ \\
\hline
\end{tabular}

Data are shown as medians with the $\mathrm{P}_{25}-\mathrm{P}_{75}$ between brackets. Data were analysed using a Mann-Whitney-U test. 
Table 2. Correlation between outcome scores, age and BMI

\begin{tabular}{lccc}
\hline Patient or fracture & VAS & $\begin{array}{c}\text { AOFAS functional } \\
\text { characteristic }\end{array}$ & $\begin{array}{c}\text { AOFAS total } \\
\text { score }\end{array}$ \\
\hline VAS & N.A. & $0.406^{*}$ & $0.530^{*}$ \\
AOFAS Functional & $0.406^{*}$ & N.A. & $0.668^{*}$ \\
score & & & \\
AOFAS total score & $0.530^{*}$ & $0.668^{*}$ & N.A. \\
Age & 0.112 & 0.041 & 0.039 \\
BMl & 0.112 & 0.160 & 0.115
\end{tabular}

Spearman Rank Correlations are given. Data were analysed using a Spearman Rank Correlation test.

${ }^{*} \mathrm{P}<0.001$

N.A., Not Applicable. 